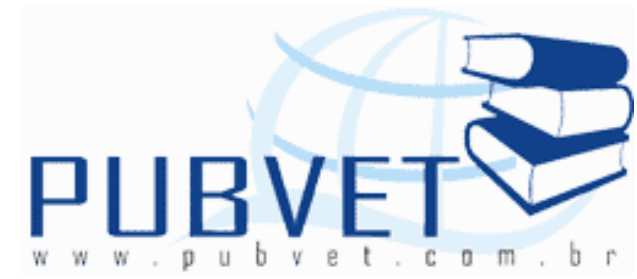

PUBVET, Publicações em Medicina Veterinária e Zootecnia.

\title{
Influência do jejum na incidência de lesão na mucosa esofágica-gástrica, peso de carcaça quente e peso de estômagos em suínos
}

Driele Schneidereit Sant'ana ${ }^{1}$, Millene Torres de Oliveira ${ }^{1}$, Luana Ribeiro Alves ${ }^{1}$, Serly Lourenço Borges Reis ${ }^{1}$, Robson Carlos Antunes ${ }^{4}$, Leonardo Gomes Carrazza ${ }^{1}$, Thaís Gomes Carrazza ${ }^{3}$, Danilo Leonel Silva²

1 Mestrando do Programa de Pós Graduação em Ciências Veterinárias da Faculdade de Medicina Veterinária da Universidade Federal de Uberlândia.

2 Zootecnista Autônomo.

3 Graduanda do curso de Medicina Veterinária da Universidade Federal de Uberlândia - UFU

${ }^{4}$ Docente Doutor da Faculdade de Medicina Veterinária da Universidade Federal de Uberlândia, Rua Pará, 1720, 38400-902, Uberlândia, Minas Gerais, Brasil. * Autor para correspondência. E-mail: robson@famev.ufu.br

\section{Resumo}

O objetivo deste trabalho foi avaliar os efeitos dos diferentes tempos de jejum ( 0 , 8 e 34 horas) no pré- abate de suínos, nas características de escore de lesão esofágica-gástrica (LEG), peso de carcaça quente (PCQ), proporção de peso de estômago cheio (PPEC) e proporção de peso de estômago vazio (PPEV), sendo o PEC e PEV proporcionais ao PCQ. Foram utilizados 90 suínos com 150 dias de idade, sendo 30 animais para cada tratamento $(\mathrm{T})$. Para a análise de escore de lesão esofágica- gástrica, foi utilizado o método estatístico de Kruskal Wallis não 
SANT'ANA, D.S. et al. Influência do jejum na incidência de lesão na mucosa esofágica-gástrica, peso de carcaça quente e peso de estômagos em suínos. PUBVET, Londrina, V. 5, N. 10, Ed. 157, Art. 1058, 2011.

paramétrico com significância de 5\%. Para as variáveis de PCQ, PPEC e PPEV, foi feita a análise de variância em delineamento inteiramente casualizado e teste de Tukey com $5 \%$ de significância para comparação das médias. A incidência de úlcera esofágica-gástrica foi maior em 0 e 34 horas de jejum, e com 8 horas houve apenas estômagos normais com paraqueratose. Não houve influência do jejum no PCQ $(p<0.05)$ e PPEC, enquanto no PPEV, houve diferença significativa entre os três tratamentos sendo T1 $(7,9), \mathrm{T} 2(4,9)$ e T3 $(5,9)$, fato explicado pela grande mobilização de líquido osmótico do corpo para o estômago, o que é proporcional ao tempo de jejum. Deve-se então dar atenção ao tempo de jejum evitando causar estresse aos animais e conseqüente perdas na carcaça.

Palavras-chave: jejum pré-abate, paraqueratose, suínos, úlcera

\section{Influence of fasting on the incidence of esophageal mucosal injury gastric, weight and hot carcass weight in pigs stomachs}

\section{Abstract}

The aim of this study was to evaluate the effects of different fasting times $(0,8$ and 34 hours) in pre-slaughter of pigs characteristics score of esophageal-gastric lesion (LEG), hot carcass weigth (PCQ), ration of full stomach weight (PPEC) and ration weight of empty stomach (PPEV), with the PEC and PEV proportional to PCQ. Was used 90 pigs at 150 days of age, 30 animals for each treatment $(T)$. For analysis of lesion score esophageal-gastric, method was used nonparametric Kruskal Wallis with $5 \%$ significance. For variables (PCQ), (PPEC) and (PPEV) was made by analysis of variance in completely randomized design and Tukey test at $5 \%$ significance level. The incidence of esophageal-gastric ulcer was higher in 0 and 34 hours of fasting, and 8 hours was the only normal stomachs and parakeratosis. There was no influence of fasting on the PCQ $(p<0.05)$ and PPEC, while in PPEV, significant differences between the treatments: T1 (7.9), T2 (4.9) and T3 (5.9), a fact explained by the great mobilization of fluid osmotic the body to the stomach, and that proportional to the time of fasting. Should then pay 
SANT'ANA, D.S. et al. Influência do jejum na incidência de lesão na mucosa esofágica-gástrica, peso de carcaça quente e peso de estômagos em suínos. PUBVET, Londrina, V. 5, N. 10, Ed. 157, Art. 1058, 2011.

attention to the time of fasting from causing stress to animal and consequent losses in the housing.

Keywords: fasting pre-slaughter, parakeratosis, pigs, canker

\section{INTRODUÇÃO}

A prática do jejum pré-abate tem muita relevância na cadeia produtiva dos suínos, que se inicia na fase de terminação na granja e termina no abate no frigorífico (Peloso, 2002). Esta prática consiste na retirada dos alimentos sólidos (ração), porém com fornecimento de água com boa qualidade e à vontade (Faucitano, 2001).

Esse manejo é fundamental, pois pode contribuir em aspectos como: economia de ração, redução na taxa de mortalidade durante o transporte, volume de dejetos, incidência de vômitos durante o transporte, aumento da velocidade e facilidade do processo de evisceração e padronização no rendimento de carcaça (Tarrant, 1991; Beattle et al., 2002; Dalla Costa et al., 2008). Além do mais, juntamente com o processo de descanso no frigorífico há uma recuperação do glicogênio muscular, que contribui para a uniformização da carne (Peloso, 2002) e a produção de carcaças de boa qualidade, baseado em avaliações de $\mathrm{pH}$, cor e perda de água (Warris et al., 1998).

Há uma grande divergência na literatura quanto a recomendações de tempo de jejum nas granjas. Gispert (2000) e Chevillon (1994), relataram que 12-18 horas é o tempo ideal já que diminui o estresse pré-abate e aumentam a qualidade da carne. Murray (2001) recomendou entre 10 e 24 horas, Eikeleboon et al. (1991) de 16 a 24 horas e Magras et al. (2000) sugeriram tempo de 22 a 28 horas, afim de resultar em suínos com menor peso estomacal $(<1.4 \mathrm{Kg})$.

A ulceração esofágica-gástrica, pode ser causa de morte súbita em suínos mantidos em sistema intensivo de produção (Ciacci et al., 1991). Em estudo feito por Friendship (1999) relatou-se que a interrupção da alimentação (o jejum), tem sido causas de lesões ulcerativas, além de fatores como: rações peletizadas, soro de leite com baixo pH na alimentação, gelatinização do milho, dietas pobres em 
SANT'ANA, D.S. et al. Influência do jejum na incidência de lesão na mucosa esofágica-gástrica, peso de carcaça quente e peso de estômagos em suínos. PUBVET, Londrina, V. 5, N. 10, Ed. 157, Art. 1058, 2011.

fibra, deficiência de vitamina E e selênio, silagem de milho mal fermentada, rações contaminadas com fungos e aflatoxinas, rações com partículas finas moídos na dieta (menores que $500 \mu$ ), fatores genéticos, confinamento, manejo inadequado como mistura de lotes e superlotação (Kavanagh, 1994 e O'brien, 1986).

Alterações como paraqueratose, erosões e ulcerações gástricas são encontradas em 43,7 a 77,4\% da população suína do Brasil (Carvalho et al., 1999). Elbers et al. (1995) relataram a $11 \%$ de incidência de lesões erosivas e ulcerativas em suínos abatidos, enquanto a paraqueratose, que afetava a pars oesophagea, foi observada em $89 \%$ dos estômagos examinados.

O objetivo deste estudo foi avaliar o efeito do tempo de jejum (0, 8 e 34 horas) de suínos no abate sobre o peso de carcaça quente (PCQ), proporção de peso de estômago cheio (PPEC), proporção de peso de estômago vazio (PPEV) e o escore de lesão na mucosa esofágica-gástrica (LEG).

\section{MATERIAL E MÉTODOS}

Foram estudados 90 suínos oriundos de cruzamentos industriais, com aproximadamente 150 dias de idade, todos da mesma granja comercial em Patos de Minas - MG. Os animais pertenciam a seguinte linhagem: 1/2 AGPIC $425^{\circledR}$ (Large White e Pietran) x 1/2 Camb. $25^{\circledR}$ (AGPIC 1062 e AGPIC 1020), sendo machos e fêmeas. O experimento foi realizado no mês de março de 2010.

O transporte dos suínos da granja ate o frigorífico foi realizado em um modelo de carroceria metálica dupla, TRIEL-HT, com capacidade de transporte de 96 animais, representando uma densidade média de $0,45 \mathrm{~m}^{2}$ animal ${ }^{-1}$ ou $288 \mathrm{~kg} \mathrm{~m}^{-}$ ${ }^{2}$ e o tempo médio de transporte dos animais da granja até o frigorífico foi de 3 horas.

Após o desembarque, os suínos foram pesados e alojados em pocilgas de descanso coletivas. No manejo pré-abate, os suínos receberam tempo de jejum na granja antes do carregamento de 12 horas e ao chegar no frigorífico todos os animais dos três tratamentos permaneceram em repouso, dieta hídrica e receberam Fubá de milho. Ao terminar toda a ração nas pocilgas os mesmos 
SANT'ANA, D.S. et al. Influência do jejum na incidência de lesão na mucosa esofágica-gástrica, peso de carcaça quente e peso de estômagos em suínos. PUBVET, Londrina, V. 5, N. 10, Ed. 157, Art. 1058, 2011.

receberam períodos de jejum de 0,8 e 34 horas, sendo 30 animais para cada jejum ou tratamento. Após esse período, os animais foram conduzidos à sala de abate e submetidos à insensibilização elétrica (ou eletro-narcose) que foi aplicada automaticamente, transferindo alta voltagem 350 volts e amperagem acima de 1,3 Amps (Remafrig Remand 1940), por 3 segundos. A sangria foi realizada imediatamente após a insensibilização, com o animal posicionado na posição vertical, obedecendo ao tempo regulamentar de três minutos (Brasil, 2000).

Prosseguiram-se as demais operações de abate normal: escaldagem a $65^{\circ} \mathrm{C}$ por cinco minutos, depilação, evisceração, divisão da carcaça e toalete (Brasil, 1952). Em seguida foram pesadas, em balança específica, no qual foi determinado o peso de carcaça quente (PCQ). Durante o processo de evisceração dos animais em avaliação, coletou-se o estômago, o qual foi pesado cheio e vazio (após a retirada do conteúdo estomacal e da limpeza com água corrente). Após a limpeza dos estômagos, os mesmos foram examinados macroscopicamente para avaliação do escore de lesão na mucosa esofágica-gástrica (LEG), seguindo classificação proposta por Morés et al. (2000). Tal avaliação foi realizada por um mesmo observador previamente treinado.

Para a análise de PEC e PEV, utilizou-se o peso proporcional do estômago cheio (PPEC) em relação ao peso de sua carcaça quente através da fórmula: $\mathrm{PPEC}=\mathrm{PEC} / \mathrm{PCQ}$, seguindo análogo para os cálculos de PEV.

$\mathrm{Na}$ análise estatística foi utilizado o método de Kruscal Wallis não paramétrico para a análise de escore de úlceras com significância de $5 \%$ comparando os três tratamentos. Para as variáveis de PPEC, PPEV e PCQ, foi feita a análise de variância em Delineamento Inteiramente Casualizado, aplicando o teste Tukey para comparação das médias com $5 \%$ de significância $(p<0,05)$, utilizando-se para ambas as análises o programa de software Biostat 5.0 (Ayres et al., 2007). 
SANT'ANA, D.S. et al. Influência do jejum na incidência de lesão na mucosa esofágica-gástrica, peso de carcaça quente e peso de estômagos em suínos. PUBVET, Londrina, V. 5, N. 10, Ed. 157, Art. 1058, 2011.

\section{RESULTADOS E DISCUSSÃO}

Em apenas um dos 90 estômagos inspecionados, foi encontrado lesões na região glandular (cárdica, fúndica e pilórica), sendo que a maior parte dos animais 98,9\% foi encontrado lesões na parte esofágica do estômago. Estas lesões estomacais que são predominantemente encontradas na região esofágica, podem ser devidas a ausência de glândulas mucosas nesta região e ao tipo de epitélio, o que o torna relativamente desprotegido contra as ações digestivas do Ácido Clorídrico ( $\mathrm{HCL}$ ) e da pepsina, que se encontram presentes no estômago (Zanotto, 1992).

O tempo de jejum dos suínos na granja influenciou significativamente no LEG sobre os animais sem jejum e com jejum de 34 horas, sendo que os animais com 34 horas de jejum, 40\% (12 suínos), apresentaram lesões de úlceras e os demais animais, lesões de paraqueratose (30\%) e erosão (30\%), (Figura 1). Esses resultados estão de acordo com os obtidos por Bidner (1999), que encontrou efeito significativo do tempo de jejum em suínos submetidos a um jejum de 12, 36 e 60 horas no escore de LEG $(0 ; 0,96$ e 1,44), sendo que $79 \%$ dos suínos que foram submetidos ao jejum de 36 horas, apresentaram lesões de paraqueratose em seus estômagos.

Os animais que foram abatidos sem o jejum, a incidência de paraqueratose, úlcera e erosão foi de 50; 30 e 13,3\%, respectivamente, enquanto somente dois animais $(6,66 \%)$, apresentaram estômagos normais sem lesão. Essa quantidade de lesões estomacais podem ter sido influenciadas pela granulometria da ração, pois os suínos foram alimentados com Fubá de Milho em que a moagem do milho foi extremamente fina e a granulometria foi de $300 \mu$ (assim como a granulometria da ração da granja que foi dada aos suínos nos últimos 20 dias de terminação, podendo então esta quantidade de lesões terem sido influenciadas desde a alimentação na granja).

Resultados de estudos feitos por Nuwer et al. (1964), nos quais os suínos foram alimentados com diferentes frações de milho grãos sugerem que a finura da ração pode ser um fator que influencia a incidência de úlcera esofágica em suínos. 
SANT'ANA, D.S. et al. Influência do jejum na incidência de lesão na mucosa esofágica-gástrica, peso de carcaça quente e peso de estômagos em suínos. PUBVET, Londrina, V. 5, N. 10, Ed. 157, Art. 1058, 2011.

Zanoto (1992), analisando os estômagos de suínos submetidos a quatro dietas diferentes quanto ao tamanho das partículas, formadas a base de milho e farelo de soja, concluiu que a moagem mais fina do milho exerceu efeito positivo no desenvolvimento de alterações epiteliais na região esofágica-gástrica dos suínos, sendo que os animais na fase de crescimento foram mais susceptíveis.

Em um outro estudo feito por Mahan et al. (1966), foi utilizado uma ração com milho expandido (alta granulometria) e outra com milho finamente moído (com baixa granulometria), e através dos resultados sugeriram que ambos os tratamentos podem contribuir para incidência de úlceras, porém lesões estomacais foram mais graves em suínos alimentados com a ração de milho expandido sendo $27,8 \%$, enquanto a ração moída $5,6 \%$.

Quanto ao jejum 8 horas (T2), não houve nenhum suíno que apresentasse LEG, apenas um animal apresentou erosão (3,3\%), e 13 animais (43,3\%) paraqueratose enquanto a maioria dos suínos $(53,3 \%)$, foi observado estômagos normais, com aspecto branco, liso e brilhante, segundo critério de O'brien (1986) para classificação de estômago normal.

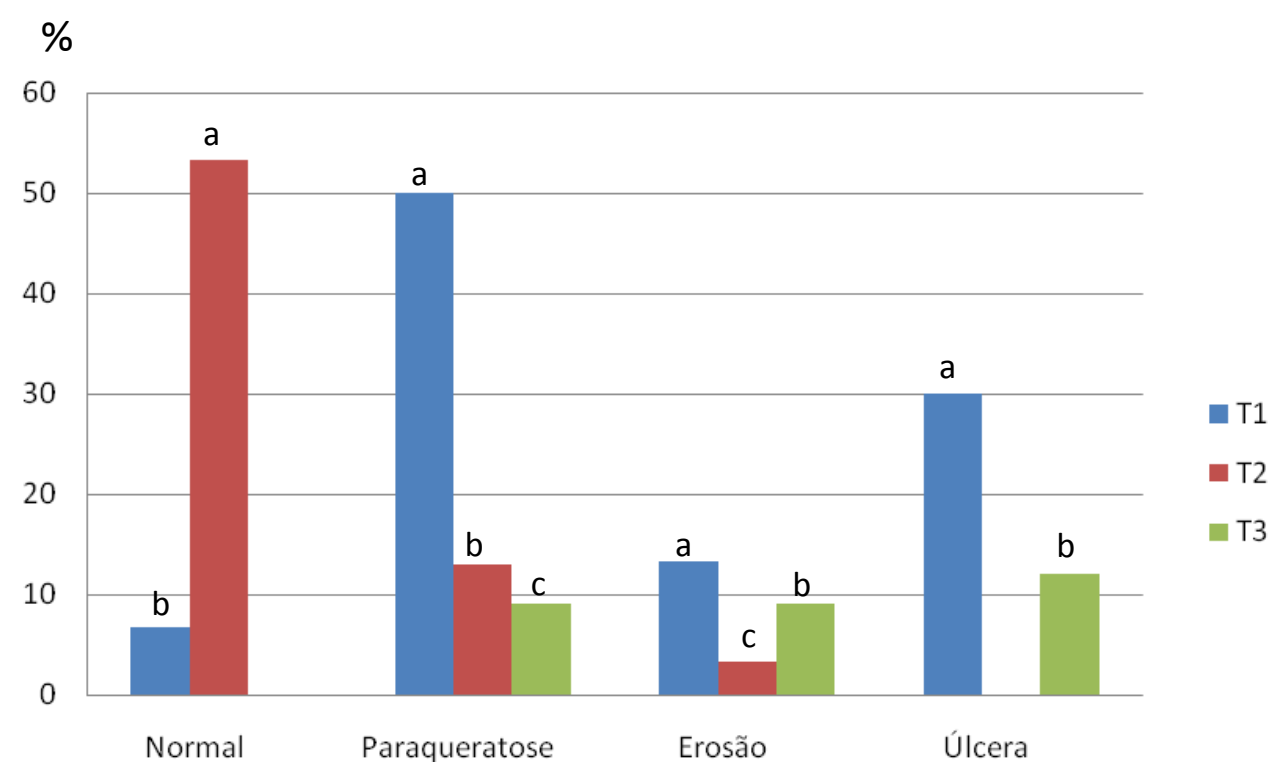

Figura 1 - Porcentagem de LEG por tratamento. Médias com letras distintas dentro de cada fator indicam diferença significativa pelo teste de Tukey $(p<0,05)$. 
SANT'ANA, D.S. et al. Influência do jejum na incidência de lesão na mucosa esofágica-gástrica, peso de carcaça quente e peso de estômagos em suínos. PUBVET, Londrina, V. 5, N. 10, Ed. 157, Art. 1058, 2011.

Os resultados do jejum normal estão de acordo com trabalho feito por Dalla Costa et al. (2008), que mostraram que o jejum de 14 a 23 horas, durante o manejo pré- abate, não é um período suficiente para desenvolvimento de LEG nos suínos, porém pode contribuir para incidência de paraqueratose nos estômagos deste animais.

Não foi observado efeito significativo dos diferentes tempos de jejum no PCQ para T1 e T3. Apenas foi observada no T2, uma diferença significativa dos demais tratamentos $(p<0,05)$. Isso pode ter ocorrido devido a uma falta de padronização dos pesos dos animais no pré-abate, pois o PCQ do lote do T2, obteve uma média de peso vivo de 93,24 Kg enquanto T1 e T3, a média de peso foi de 77,3 e $77,8 \mathrm{Kg}$, respectivamente (Figura 2).

Em relação ao PPEC, os tratamentos T1, T2 e T3 não diferenciaram significativamente $(p>0.05)$. Os tratamentos 2 e 3 se equiparam ao 1 porque, devido a um princípio de estresse sofrido pelos animais do T2 e estresse prolongado pelos animais do T3, há uma grande mobilização de líquido osmótico em direção ao trato gastrintestinal, proporcionando uma certa equivalência de peso em relação ao estômago dos animais do tratamento 1 que estavam alimentados. Esses dados concordam com Murray et al. (2001) e Dalla costa et al. (2006) que também não encontraram efeito significativo do período de jejum sobre o PPEC.

No entanto resultados diferentes foram encontrados quando se avaliou a influência do jejum sobre PPEV. Todos os tratamentos diferiram entre si estatisticamente $(P<0.05)$, (Figura 2$)$. Esse resultado explica-se devido ao fato de que, no $T 1$, estando o estômago em condições fisiológicas normais, o esvaziamento se deu por completo. Porém nos tratamentos 2 e 3, devido ao estresse e a conseqüente mobilização de líquido osmótico em direção ao trato gastrintestinais, não foi possível retirar por completo o conteúdo osmótico, pois parte dos mesmo ficou retido nas camadas intermembranares do estômago. Nesse sentido, infere-se que quanto maior o tempo de jejum, maior será a mobilização de líquido osmótico segundo, Devlin (2007), o que justifica os estômagos do T3 
SANT'ANA, D.S. et al. Influência do jejum na incidência de lesão na mucosa esofágica-gástrica, peso de carcaça quente e peso de estômagos em suínos. PUBVET, Londrina, V. 5, N. 10, Ed. 157, Art. 1058, 2011.

pesarem mais do que os estômagos, de T2. Já o T1, devido a ausência de jejum e a conseqüente manutenção do equilíbrio metabólico o peso dos estômagos foi maior do que nos demais tratamentos.

(g)

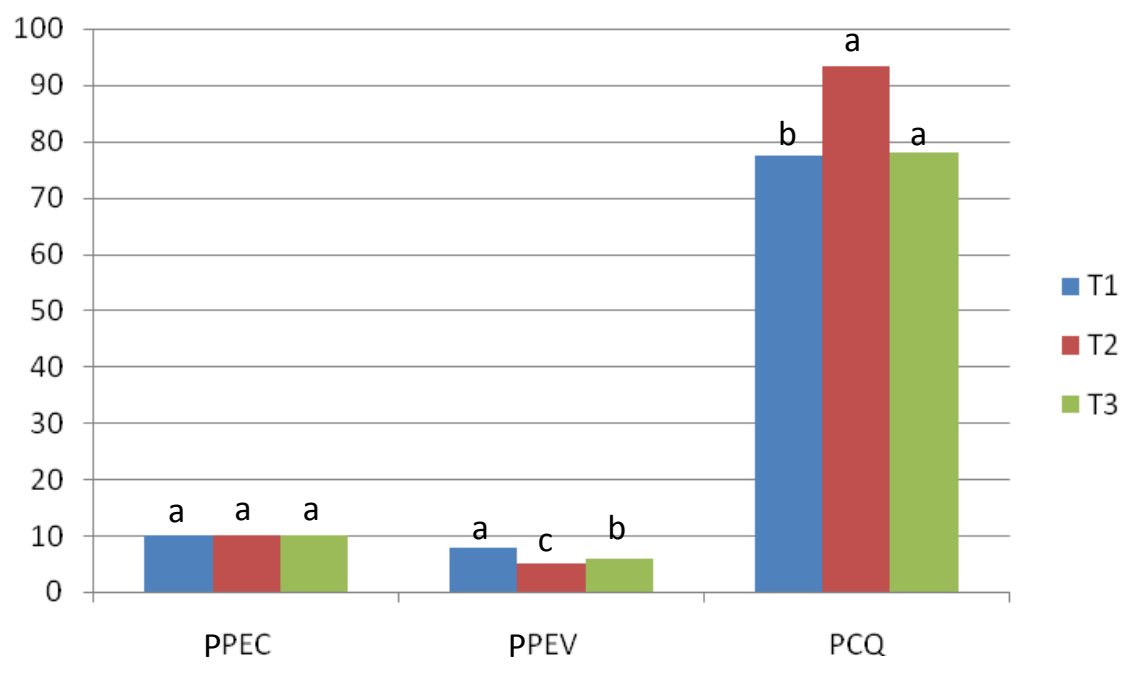

Figura 2 - Médias ajustadas do PPEV, PPEC E PCQ em gramas (g), por período de jejum dos suínos na granja. Médias com letras distintas dentro de cada fator indicam diferença significativa pelo teste de Tukey $(p<0,05)$.

\section{CONCLUSÕES}

Os diferentes tempos de jejum influenciaram na alta incidência de úlcera esofágica-gástrica, apenas para os jejuns de 0 e 34 horas. Devendo-se então, dar atenção especial a granulometria da ração (para que não haja um desenvolvimento de lesões estomacais) e ao tempo de jejum, visto que o mesmo sendo feito em tempo adequado, visa o bem estar dos animais, consequentemente evita maiores perdas qualitativas e quantitativas. 
SANT'ANA, D.S. et al. Influência do jejum na incidência de lesão na mucosa esofágica-gástrica, peso de carcaça quente e peso de estômagos em suínos. PUBVET, Londrina, V. 5, N. 10, Ed. 157, Art. 1058, 2011.

\section{REFERÊNCIAS}

AYRES, M.; AYRES Jr, M.; AYRES, D. L.; SANTOS, A. S. dos. BioEstat 5.0: Aplicações estatísticas nas áreas das ciências biológicas e médicas. Belém: Sociedade Civil Mamirauá; Brasília: CNPq, 2007, 324 p.

BEATTIE, V. E.; BURROWS, M. S.; MOSS, B. W.; WEATHERUP, R. N. The effect of food deprivation prior to slaughter on performance, behavior and meat quality. Meat Science, Kidlington, v. 62, p. $414-418,2002$.

BIDNER, E. S. The effects of RN genotype, feed withdrawal prior to slaughter, lysinedeficient diet, and sodium tripolyphosphate, pumping on pork quality and sensory characteristics. 1999. 91f. Dissertação (Mestrado em Zootecnia) - University Illinois.

BRASIL, Instrução Normativa No 03. Regulamento Técnico de Métodos de Insensibilização para o Abate de Animais de Açougue. Brasília: M.A.A., 1952. Diário Oficial da União, Brasília, DF, 2000, Seção 1, p.14.

CARVALHO, L. F. O. S.; OliveirA, C. J. B.; MARTINEZ, P. A. O.; MAZZUCATO, B. C.; AleSSi, A. C. Freqüência de lesões gástricas em suínos destinados ao abate na região de Ribeirão Preto, SP. Arquivo Brasileiro de Medicina Veterinária e Zootecnia, v.51, p.223-227, 1999.

CHEVILLON, P. Le contrôledesestomacs de porcs à l'abattoir: miroir de La mise à jeunenélevage. Techini-Porc, v. 17, p. 23-30, 1994.

CIACCI, J. R.; MORES, N.; SOBESTIANSKY, J. Úlcera gástrica como causa de morte e como achado de necropsia em três rebanhos suínos. Arquivo Brasileiro de Medicina Veterinária e Zootecnia, v.43, p.525-533, 1991.

DALLA COSTA, O. A. Efeitos do manejo pré-abate no bem-estar e na qualidade de carne de suínos. 2006. 162 f. Tese de Doutorado em Zootecnia, Faculdade de Ciências Agrárias e Veterinárias, Universidade Estadual Paulista, Jaboticabal, SP, 2006.

DALLA COSTA, O. A.; COSTA, M. J. R. P.; LUDKE, J. V.; COLDEBELLA, A.; KICH, J. D.; PELOSO, J. V.; FAUCITANO, L.; ROZA, D. D. Tempo de jejum dos suínos no manejo pré-abate sobre a perda de peso corporal, o peso do conteúdo estomacal e a incidência de úlcera esofágica-gástrica. Ciência Rural, Santa Maria. v.38, n.1, p. 199-205, jan-fev, 2008.

DEVLIN, T. M. Manual de Bioquímica com correlações clínicas. Ed.6. P. 1216. Ano 2007.

EIKELENBOON, G.; BOLINK, A. H.; SYSBENA, E. Effects of feed withdrawal before delivery on pork quality and carcass yield. Meat Science, Kidlington, v. 29, p. 25-30, 1991.

ELBERS, A. R. W., HESSING, M. J. C., TIELEN, M. J. M.; VOS, J. H. Growth and oesophagogastric lesions in finishing pigs offered pelleted feed ad libitum. Veterinary Research, v.136, p.588-590, 1995.

FAUCITANO, L. Efeitos do manuseio pré-abate sobre o bem-estar e sua influência sobre a qualidade da carne. In: CONFERÊNCIA VIRTUAL INTERNACIONAL SOBRE QUALIDADE DA CARNE SUÍNA, 1., 2000, Concórdia. Anais... Concórdia: EMBRAPA Suínos e Aves, 2001, p. 55-75

FRIENDSHIP R. 1999. Gastric ulcers.In: Straw B.E., Dallaire S., Mengeling L. \& Taylor D.J. (Eds). Diseases of swine. Ames: Iowa State University Press, p. 685-694 
SANT'ANA, D.S. et al. Influência do jejum na incidência de lesão na mucosa esofágica-gástrica, peso de carcaça quente e peso de estômagos em suínos. PUBVET, Londrina, V. 5, N. 10, Ed. 157, Art. 1058, 2011.

GISPERT, M. M.; FAUCITANO, L.; OLIVER, M. A.; GUÀRDIA, M. D.; COLL , C.; SIGGENS, K.; HARVEY, K.; DIESTRE, A. A survey of pre-slaughter conditions, halothane gene frequency, and carcass and meat quality in five Spanish pig commercial abattoirs. Meat Science, Kidlington, $v$. 55, p. 97-106, 2000.

KAVANAGH, N. Gastric ulcers in pigs.In Pratice, v.16, n.4, p. 209-13, 1994.

MAGRAS, C.; DELAUNAY, I.; BÉNÉTEAU, E. Quelles durées de mise à jeun dês porcs charcutiers pour um optimun de qualité dês carcasses? Détermination à partir dún étude terrain. Jounées Recherche Porcine em France, v.32, p. 351-356, 2000.

MAHAN, D. C.; PICKETT, R. A.; PERRY, T. W. ; CURTIN, T.; FEATHERSTON,W. R.; BESSON, W. M. Influence of various nutritional factors and physical form of feed on esophagogastric ulcer in swine. Journal of Animal Science, v.25, p.1019-1023, 1966.

MORÉS, N.; SOBESIANSKY, J.; LOPEZ. A. C. Avaliação patológica de suínos no abate manual de identificação. Brasília: Embrapa Comunicação para Transferência de tecnologia, 2000. 40p.

MURRAY, C.; ROBERTSON, W.; NATTRESS, F.; FORTIN, A. Effect of preslaughter overnight feed withdrawal on pig carcass and muscle quality. Canadian Journal of Animal Science, v.81, p.8997, 2001.

NUWER, A. J.; PERRY, T. W.; PICKETT, R. A.; FEATHERSTON, W. R.; CURTIN, T. M.; BEESON, W.M. Effect of heat processing of various corn fractions on occurrence of ulcers in swine. Journal of Animal Science. 23. 887(Abst.), 1964.

O'BRIEN, J. J. Gastric ulcers. In: LEMAN, A.D. et al. (Ed.) Disease of Swine, 6 ed. Ames: Iowa State University Press. p.725-37, 1986.

PELOSO, J. V. Influência do jejum pré-abate sobre a condição muscular em suínos e seus efeitos na qualidade final da carne para industrialização. In: CONFERÊNCIA VIRTUAL INTERNACIONAL SOBRE QUALIDADE DA CARNE SUÍNA, v.2. 2001, Concórdia. Anais... Concórdia: EMBRAPA Suínos e Aves, 2002. p. 385-392.

TARRANT, P. V. The last feed before slaughter .Pig International, n.21, p.39-41, 1991.

WARRIS, P. D.; BROWN, S.; EDWARDS, J.; KNOWLES, T. Effect of lairage time on levels of stress and meat quality in pigs. Animal Science, v.66, p.255-261, 1998

ZANOTTO, D. L. Granulometria do milho em rações para suínos em crescimento e terminação. Digestibilidade, desempenho, e alterações gástricas. Concórdia, 1992, 83p. Dissertação (Mestrado em EMBRAPA - CNPSA). 